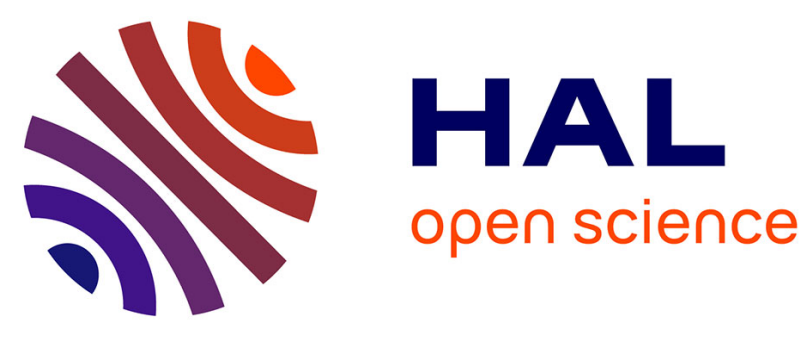

\title{
Entrain, exploring new territorial user interfaces
}

Anne-Marie Déry-Pinna, Philippe Renevier Gonin, Marco Winckler, Christophe Kolski, Sophie Lepreux, Jean Vanderdonckt

\section{To cite this version:}

Anne-Marie Déry-Pinna, Philippe Renevier Gonin, Marco Winckler, Christophe Kolski, Sophie Lepreux, et al.. Entrain, exploring new territorial user interfaces. EICS 2020 - 12th ACM SIGCHI Symposium on Engineering Interactive Computing Systems, ACM SigCHI : Special Interest Group on Computer-Human Interaction, Jun 2020, Nice, France. pp.1-4, 10.1145/3393672.3398648 . hal03138763

\section{HAL Id: hal-03138763 https://hal.science/hal-03138763}

Submitted on 12 Oct 2021

HAL is a multi-disciplinary open access archive for the deposit and dissemination of scientific research documents, whether they are published or not. The documents may come from teaching and research institutions in France or abroad, or from public or private research centers.
L'archive ouverte pluridisciplinaire HAL, est destinée au dépôt et à la diffusion de documents scientifiques de niveau recherche, publiés ou non, émanant des établissements d'enseignement et de recherche français ou étrangers, des laboratoires publics ou privés. 


\section{ENTRAIN, Exploring New Territorial User Interfaces}

\author{
Anne-Marie Dery-Pinna, Philippe \\ Renevier Gonin, Marco Winckler \\ Ecole Polytechnique Universitaire de \\ Sophia-Antipolis \\ Laboratoire I3S-CNRS-URA 1376 \\ Sophia-Antipolis Cedex, France \\ firstname.lastname@univ-cotedazur.
} fr

\author{
Christophe Kolski, Sophie \\ Lepreux
}

Univ. Polytechnique Hauts-de-France LAMIH-UMR CNRS 8201

Valenciennes Cedex 9, France firstname.lastname@uphf.fr

\author{
Jean Vanderdonckt \\ Université catholique de Louvain \\ (UCLouvain) \\ Louvain Research Institute in \\ Management and Organizations \\ (LouRIM Institute) \\ Louvain-la-Neuve, Belgium \\ jean.vanderdonckt@uclouvain.be
}

\begin{abstract}
We aim at exploring the different approaches to design interactive applications for groups of users using a set of interacting surfaces to perform their tasks with an optimal user experience. Participants are invited to present both the models and/or design methods as well as the case studies and applications they are studying in this context. We would like to set up a discussion group in order to put each person's work in perspective with the notion of territoriality applied to ambient computing and multiple devices. The territoriality theory may serve as a basis for the design of complex interactive applications of quality. From these discussions will emerge a mapping of models and design methods that could be mutualized and combined.
\end{abstract}

\section{CCS CONCEPTS}

- Human-centered computing $\rightarrow H C I$ design and evaluation methods; Graphical user interfaces; Collaborative interaction; Displays and imagers; Interactive systems and tools; • Software and its engineering $\rightarrow$ Distributed systems organizing principles; - Computing methodologies $\rightarrow$ Distributed computing methodologies;

\section{KEYWORDS}

Design Space, Distributed User Interfaces, Interaction surface, Model-based approach, Multi-surface interaction, Territoriality, Territorial User Interfaces.

\section{ACM Reference Format:}

Anne-Marie Dery-Pinna, Philippe Renevier Gonin, Marco Winckler, Christophe Kolski, Sophie Lepreux, and Jean Vanderdonckt. 2020. Entrain, Exploring New Territorial User Interfaces. In $A C M$

Permission to make digital or hard copies of part or all of this work for personal or classroom use is granted without fee provided that copies are not made or distributed for profit or commercial advantage and that copies bear this notice and the full citation on the first page. Copyrights for thirdparty components of this work must be honored. For all other uses, contact the owner/author(s).

EICS '20 Companion, fune 23-26, 2020, Sophia Antipolis, France

(c) 2020 Copyright held by the owner/author(s)

ACM ISBN 978-1-4503-7984-7/20/06

https://doi.org/10.1145/3393672.3398648
SIGCHI Symposium on Engineering Interactive Computing Systems (EICS '20 Companion), June 23-26, 2020, Sophia Antipolis, France. ACM, New York, NY, USA, 4 pages. https://doi.org/10.1145/3393672. 3398648

\section{INTRODUCTION AND BACKGROUND}

As interactive and connected devices become more and more varied [15], user interfaces are becoming more and more distributed $[1,13,16]$. Interactive applications therefore increasingly involve groups of users interacting with a set of interaction surfaces to carry out their tasks. The definition of design spaces, models and design methods have proven themselves in HCI design in the fields of plasticity, multi-modality, distributed interfaces. As in proxemic interaction [12], territorial user interfaces are governed by several parameters, such as location, partitioning, and orientation. The design methods most often exploit models and rules to propose a step-wise structured approach that leads to all or part of the interactive computer application. Such models assume to provide answers to the following questions:

- What are the specific data to an application domain (e.g., road traffic) and the constraints imposed on that domain?

- What are the tasks to be performed? What are the low-level actions (e.g., create, delete, modify, search) and the high-level tasks (e.g., putting a car on a road network?

- Which users are involved in these tasks, depending on their roles (not fixed in time) in the groups?

- Which devices are used (e.g., from the smartphone to the large wall screen)?

- Which software platforms are used (e.g., what operating systems, what data exchange protocols are planned)?

- How is the physical environment in which the users are when performing their interactive tasks using the provided devices?

In order to design interactive applications dedicated to groups of users interacting with a set of interaction surfaces to carry out their tasks in complex environments, like museums, public places, offices, theatres, with a quality user 


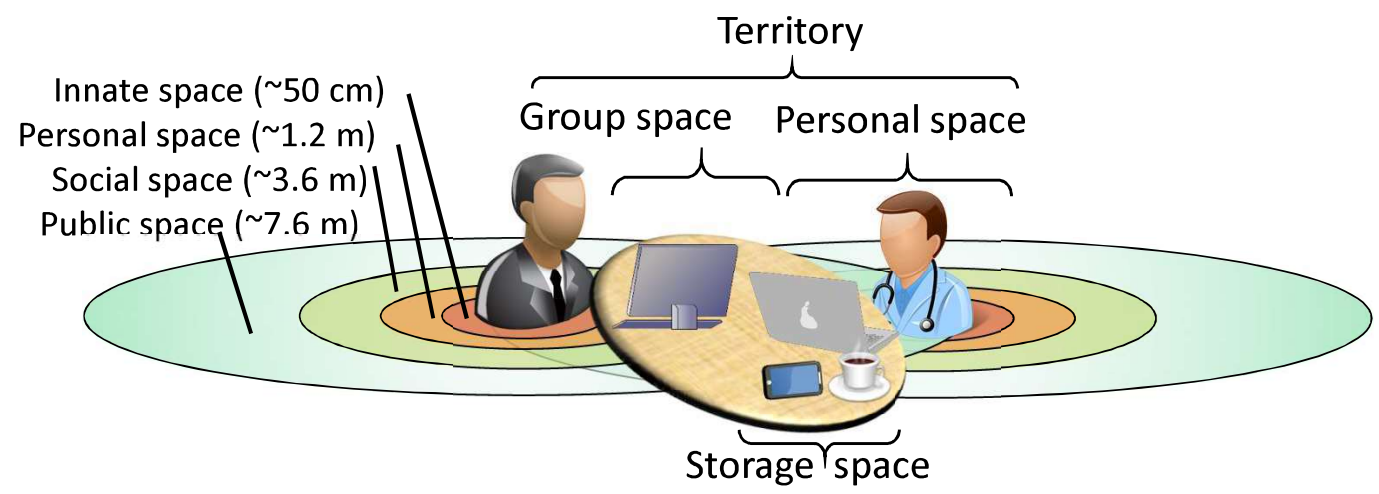

Figure 1: The concept of territoriality in UI design.

experience, we wish in this workshop to share the problems encountered and the solutions provided or envisaged. To this end, we wish to put submitted works in perspective with the notion of territoriality applied to ambient computing and multiple devices. The territoriality theory may serve as a basis for the design of complex interactive applications of quality.

Indeed the distribution of information is studied in the theory of territoriality for interactive tabletops $[6-8,16,17]$. The theory of territoriality [16] (See Figure 1) is indeed used to interpret the partitioning practices of the workspace constituted by the tabletop. Partitioning the workspace thus amounts to delimiting and managing different territories on the tabletop. Scott and Carpendale [16] distinguish three types of territory:

(1) Personal territories, which are used to carry out autonomous activities/tasks (e.g. reading, writing and classifying resource items); they are also important in collaboration because they "provide a visible and accessible area for other members of the group, allowing them to follow the autonomous activities of a teammate";

(2) Group territories, which provide group members with a space to work on the product of the task and to help each other;

(3) Storage territories, which allow to organize the resource elements on the table; they can be created on auxiliary surfaces that can be moved around the table.

A fourth type of territory is introduced by Li, Greenberg et Sharlin [11]: private territories, which are neither visible nor changeable publicly. Each territory combines three main characteristics [16]: (1) its purpose; (2) the typical activities or interactions it allows; (3) its spatial properties (size and shape). Territorial behavior is "based on perceived, attempted, or actual control of a definable physical space, object, or idea" [16]. The perception, partitioning, establishment, maintenance or change of territory (or transition between territories) are examples of territorial behavior.
Contributions from participants can help:

- To establish a literature review on the potential implications of the concept of territoriality in computer science.

- To make the link between the concept of territoriality and that of distributed interfaces,

- To list the models that could be used to design and develop the type of interactive applications targeted.

- To propose a method for developing interfaces by identifying input and output elements, guidelines and constraints to be respected.

- To identify case studies that can illustrate the problem and proposed solutions.

\section{WORKSHOP OVERVIEW}

Due to Covid-19 pandemic situation, the EICS 2020 Conference is canceled. So we reschedule the Workshop Organisation.

\section{Workshop sessions dates}

- Entrain, session 1 - initial contact: June, the 23th 2020: a remotely session

- Entrain, session 2 - thorough work: November, the 26th and the 27th 2020: at University Côte d'Azur (Nice, France), in face-to-face presentations if possible, remotely otherwise.

\section{Workshop contributions}

These two sessions are aimed towards gathering participants who are concerned by Models and Design Methods for Multi Surfaces User Interfaces especially excited about the opportunity to gather experiences around the territoriality notion.

Participants will be invited to submit an abstract on topics such as: the use of the concept of territoriality in the context of a distributed or non-distributed interactive application, the use of model definition in interactive applications for a group of users interacting with a set of interactive surfaces to perform their tasks, the use or definition of development 
methods, rules, guidelines for interfaces on multi-surfaces, case studies to illustrate the problem and proposals for solutions in areas such as games, crisis management, collaborative design, trips in public places.

\section{Workshop selection}

- For the June session, we will select participants based on their positioning relative to the topic. Submit your positioning on the online form: https://bit.ly/nomos-2020-06-23

- For the November session, we will select up to 20 contributions. The workshop will begin with flash presentations. We will provide a consistent format for the presentations. We will discuss in sub-groups to put the work and the notion of territoriality into perspective. We will meet to synthesize the results of the groups as a mapping of each proposed models or approaches. We will establish a future research agenda.

\section{Workshop website}

The initiative web site is accessible at https://nomos.i3s.unice. $\mathrm{fr} / \mathrm{fr} /$ node $/ 10$.

\section{ORGANIZERS}

The organizers of this Workshop are partners of the NOMOS project supported by the Hubert Curien Partnership Tournesol program which facilitates scientific cooperation between France and Belgium: Prof. M. Winckler, AM Dety Pinna and P. Renevier Gonin assistant professors in the I3S laboratory; S. Lepreux assistant professor and C. Kolski professor in the LAMIH laboratory UMR CNRS 8201, UPHF; J. Vanderdonckt professor in Université Catholique de Louvain (UCLouvain).

In ancient Greek, Nomos (ópo, "law" or "custom") derives its etymology from the verb ' $\mu$ (to dispense or to allot), with Nomos being the result of allotment or the manner of allotment or dispensing. We used this metaphor to express the concept of territorial user interface, a novel type of a distributed user interface that is regulated not by the physical principles of platforms or the implementation constraints imposed by widgets, but by the interpersonal space end users have among themselves.

The I3S team is basing part of its work on the composition of IU on model engineering [3-5]. The publications [10], [9] and [1] attest to the knowledge of LAMIH in terms of tangible interaction and multi-surface interfaces. The I3S and LAMIH laboratories explore the notion of territory in the design of distributed interfaces [5].

Jean Vanderdonckt is full professor in information systems leading the Louvain Interaction Lab, Universite catholique de Louvain, Belgium. His research focuses on the contextual adaptation of user interfaces [14] and intelligent techniques to support the adaptation of user interfaces at the time of design and/or execution [2]. He is a past president of the ACM IUI '04 conference and is co-chair of the ACM EICS '20 Full Papers conference.

\section{FUTURE DIRECTIONS}

The key outcomes of the workshop will be shared online, as a blog post on the workshop webpage. In addition, we also plan to organize a follow-up workshop in 2021 with a similar theme. This is aimed towards not only ensuring continual exchange and collaboration among the participants, but also to attract other members of the wider HCI community who might not be present at EICS.

A "white paper" synthesizing the results of the workshop can be considered if it is conclusive. In the longer term, a book in the HCI series could be considered, once sufficient contributions have been received.

\section{ACKNOWLEDGEMENTS}

The authors would like to acknowledge the support to this activity by the Nomos (Nouvelle Oganisation de Modèles Orientés Surface pour la conception de systèmes interactifs basés sur la territorialité), Hubert Curien programme (2020, first edition) and Wallonie Bruxelles International under convention PAD/CCA/SCU/AJO/ADD/FR/SORT/2019/545410.

\section{REFERENCES}

[1] Amira Bouabid, Sophie Lepreux, and Christophe Kolski. 2019. Design and evaluation of distributed user interfaces between tangible tabletops. Universal Access in the Information Society 18, 4 (01 Nov 2019), 801-819. https://doi.org/10.1007/s10209-017-0602-4

[2] Sarah Bouzit, Gaëlle Calvary, Joëlle Coutaz, Denis Chêne, Eric Petit, and Jean Vanderdonckt. 2017. The PDA-LPA design space for user interface adaptation. In Proc. of the 11th IEEE Int. Conf. on Research Challenges in Information Science (RCIS '17). 353-364. https://doi.org/ 10.1109/RCIS.2017.7956559

[3] Christian Brel, Philippe Renevier-Gonin, Alain Giboin, Michel Riveill, and Anne-Marie Dery. 2014. Reusing and Combining UI, Task and Software Component Models to Compose New Applications. In Proc. of BCS-HCI '14.

[4] Anne-Marie Dery-Pinna, Jérémy Fierstone, and Emmanuel Picard. 2003. Component Model and Programming: A First Step to Manage Human Computer Interaction Adaptation. In Human-Computer Interaction with Mobile Devices and Services, Luca Chittaro (Ed.). Springer, Berlin, Heidelberg, 456-460.

[5] Anne-Marie Dery-Pinna, Sophie Lepreux, Alain Giboin, and Philippe Renevier Gonin. 2019. Territories and Distributed HCI: Refining Rules and a Method for Designing Multi-Device Games. In Proceedings of the 31st Conference on l'Interaction Homme-Machine: Adjunct (IHM '19). Association for Computing Machinery, New York, NY, USA, Article 8, 7 pages. https://doi.org/10.1145/3366551.3370347

[6] Julian Edney. 1976. Human Territories: Comment on Functional Properties: Environment and Behavior. Environment and Behavior 8, 1 (1976), 31-47. https://doi.org/10.1177/001391657600800109

[7] Mirko Fetter, David Bimamisa, and Tom Gross. 2016. Task-Based Focus and AdHoc-Focus-Territory: Novel Concepts for Shared Interactive Surfaces. In Proceedings of the 2016 CHI Conference Extended Abstracts 
on Human Factors in Computing Systems (CHI EA '16). Association for Computing Machinery, New York, NY, USA, 1193-1200. https: //doi.org/10.1145/2851581.2892446

[8] Daniel Klinkhammer, Magdalena Mateescu, Carmen Zahn, and Harald Reiterer. 2018. Mine, Yours, Ours: Coordination through Workspace Arrangements and Territoriality in Tabletop Interaction. In Proceedings of the 17th International Conference on Mobile and Ubiquitous Multimedia (MUM 2018). Association for Computing Machinery, New York, NY, USA, 171-182. https://doi.org/10.1145/3282894.3282902

[9] Sébastien Kubicki, Sophie Lepreux, and Christophe Kolski. 2012. RFIDdriven situation awareness on TangiSense, a table interacting with tangible objects. Personal and Ubiquitous Computing 16, 8 (2012), 10791094.

[10] Sophie Lepreux and Jean Vanderdonckt. 2007. Towards A Support of User Interface Design By Composition Rules. In Computer-Aided Design of User Interfaces V, Gaëlle Calvary, Costin Pribeanu, Giuseppe Santucci, and Jean Vanderdonckt (Eds.). Springer, Dordrecht, 231-244.

[11] Jiannan Li, Saul Greenberg, and Ehud Sharlin. 2017. A two-sided collaborative transparent display supporting workspace awareness. International fournal of Human-Computer Studies 101 (2017), 23 - 44. https://doi.org/10.1016/j.ijhcs.2017.01.003

[12] Saul Marquardt, Nicolai Greenberg. 2015. Proxemic Interactions: From Theory to Practice. Synthesis Lectures on Human-Centered Informatics 8, 1 (2015), 1-199. https://doi.org/10.2200/s00619ed1v01y201502hci025
[13] Jérémie Melchior, Jean Vanderdonckt, and Peter Van Roy. 2011. A Model-Based Approach for Distributed User Interfaces. In Proceedings of the 3rd ACM SIGCHI Symposium on Engineering Interactive Computing Systems (EICS '11). Association for Computing Machinery, New York, NY, USA, 11--20. https://doi.org/10.1145/1996461.1996488

[14] Vivian Genaro Motti and Jean Vanderdonckt. 2013. A computational framework for context-aware adaptation of user interfaces. In Proc. of the 7th IEEE Int. Conf. on Research Challenges in Information Science (RCIS '13). 1-12. https://doi.org/10.1109/RCIS.2013.6577709

[15] Stephanie Santosa and Daniel Wigdor. 2013. A Field Study of MultiDevice Workflows in Distributed Workspaces. In Proceedings of the 2013 ACM International foint Conference on Pervasive and Ubiquitous Computing (UbiComp '13). Association for Computing Machinery, New York, NY, USA, 63--72. https://doi.org/10.1145/2493432.2493476

[16] Stacey D. Scott, M. Sheelagh T. Carpendale, and Kori M. Inkpen. 2004. Territoriality in Collaborative Tabletop Workspaces. In Proceedings of the 2004 ACM Conference on Computer Supported Cooperative Work (CSCW '04). ACM, New York, NY, USA, 294-303. https://doi.org/10. $1145 / 1031607.1031655$

[17] Jennifer Thom-Santelli. 2009. Expressing Territoriality in Collaborative Activity. In Proceedings of the ACM 2009 International Conference on Supporting Group Work (GROUP '09). ACM, New York, NY, USA, 389390. https://doi.org/10.1145/1531674.1531738 